\title{
Automatic Judgment of Ultrasonic Detection for Solid Axle Inlaid Part
}

Kai Yang ( $\square$ yangkai_swjtu@163.com )

Chengdu Lead software technology Co., Ltd.

Dongdong Wu

Chengdu Lead software technology Co., Ltd

Liming Xie

Chengdu Tiean technology Co., Ltd

\section{Original Article}

Keywords: axle inlaid part, automatic judgment, ultrasonic, wavelet

Posted Date: November 5th, 2020

DOl: https://doi.org/10.21203/rs.3.rs-101800/v1

License: (1) This work is licensed under a Creative Commons Attribution 4.0 International License.

Read Full License 
DOI:

\title{
Automatic judgment of ultrasonic detection for solid axle inlaid part
}

\author{
YANG Kai $^{1, *}$ WU Dong-dong ${ }^{2}$ XIE Li-ming ${ }^{3}$ \\ 1 School of Physical Science and Technology, Southwest Jiaotong University, \\ Chengdu 610031, China; \\ 2 Chengdu Lead software technology Co., Ltd, Chengdu 610091, China \\ 3 Chengdu Tiean technology Co., Ltd, Chengdu 610091, China
}

Received October 12, 2020; revised December xx, xxxx; accepted January xx, xxxx

\begin{abstract}
Ultrasonic detection is the most effective nondestructive method for axle inlaid part, which has high efficiency and wide coverage. In the process of rail vehicle running, the influence of the external environment and the interaction between wheel and axle cause uneven distribution of stress concentration and with fretting corrosion, which lead to the generation of fatigue crack, otherwise, the waveform of ultrasonic detection is complex, because the energy of non-defect is too high to identify the defect. In view of this phenomenon, the ultrasonic echo data is analyzed by wavelet transform method to extract the defect characteristic, which is used for automatically judgment. The results show that the fatigue defect can be identified effectively by using the defect characteristic that extracted by wavelet transform method.
\end{abstract}

Key words : axle inlaid part; automatic judgment; ultrasonic; wavelet

\section{实心车轴镶入部超声波检测的自动判伤}

杨凯 ${ }^{1}$ 武冬冬 ${ }^{2}$ 谢利明 $^{3}$

(1. 西南交通大学物理科学与技术学院, 四川成都 610031; 2. 成都主导软件技术有限公司, 四川成都 610091；3.成都铁安科技有限责任公司，四川成都 610091）

摘 要: 车轴镶入部的无损检测方法中超声波检测为当前最为有效的方法, 不仅检测效 率高, 同时扫查覆盖面广, 但是在轨道车辆运营过程中, 由于轮轴间的相互作用及外部环境 的影响, 造成轮轴间应力集中及分布不均和微动腐蚀, 不仅会促成疲劳裂纹的产生, 同时导 致超声波检测回波中波形组成复杂，且非缺陷波形反射能量较大，严重影响了缺陷波形的辨 


\section{CHINESE JOURNAL OF MECHANICAL ENGINEERING}

Vol. xx No. x, 2020

别。针对此现象, 对超声波检测回波进行小波数据分析并提取疲劳缺陷有效特征信息，以作 为自动判伤的依据。结果表明: 使用小波提取的缺陷有效特征作为自动判伤的依据, 可以有 效地判别出疲劳缺陷并标记其所处位置。

关键词: 车轴镶入部; 自动判伤; 超声波; 小波

\section{Introduction}

The function of vehicle axle is to carry and run the vehicle, in the daily operation process, stress distribution of axle is complex, because there are bending alternating stress between the wheel and axle with the accompanying change vehicle conditions and natural environment conditions, causing surface of axle inlaid part to form micro fretting corrosion[1][2]. Under the above conditions combination, axle inlaid part have a high incidence of fatigue crack defects, and fatigue crack defects often occur in a small area, and hiding underneath the wheel. In order to find the fatigue crack in time without disassembling of wheel-set, axle must be detected regularly by ultrasonic method, preventing the expansion of fatigue crack[3] which can lead to shaft breakage, derailment and other potentially catastrophic consequences.

With the development of ultrasonic detection technology, the detection of the axle was carried out by early artificial detection armed with conventional ultrasonic probe which step by step replaced by automated phased array ultrasonic[4]detection technology[5], realizing the function of automation of electronical scan, such as beam group, wide range, more focus and so on, improving the detection efficiency, scan range, defect detection capability and stability, avoiding man-made factors.

However, at present, the main method of identifying defects is still the judgement of the amplitude and shape of abnormal waveform of detection. In practice, it is difficult to operate and the accuracy is low, because the interference assembly of wheel and axle, grain size of material, oil and rust penetration will generate high-energy waveform, resulting in defects are extremely difficult to be identified.

In this paper, a method of automatic judgment of ultrasonic detection for solid axle inlaid part is proposed, which is based on the wavelet transform decomposition of ultrasonic detection data to extract the effective characteristic information of defects, which is used to automatically judge detection data for identifying whether there are defects.

\section{Detection of axle inlaid part}

\subsection{Ultrasonic detection of axle inlaid part}

Sensitivity calibration of ultrasonic system which include instrument and probe should be done before the formal detection procedure, the properties of calibration specimen which contains certain depth of the artificial crack defects should be the same or similar to the axle. 


\section{CHINESE JOURNAL OF MECHANICAL ENGINEERING}

Vol. xx No. x, 2020

The calibration process is finished when the waveform amplitude of defects get to specified value by adjusting the gain which is calibration gain, then add certain coupling compensation gain to get the formal detection gain.
Conventional manual ultrasonic detection result, as shown in the figure 1, displaying the amplitude, shape and known fixed echo as reference to identify defects.

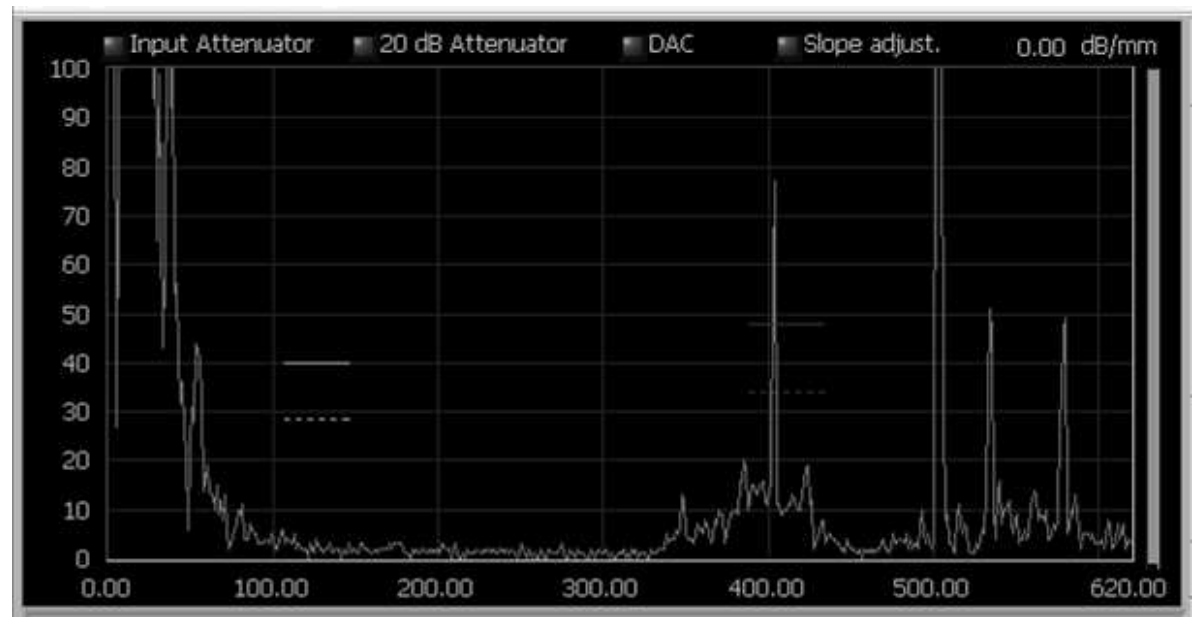

Fig.1 Conventional ultrasonic detection result(A-scan)

As shown in the figure below, the result of sensitivity calibration of automatic ultrasonic detection equipment for solid axle. There are dozens of artificial defects on the inlaid part of calibration axle, which can be identified automatically. The display of detection result is axial cutting diagram of the axle and very visualized and intuitive.

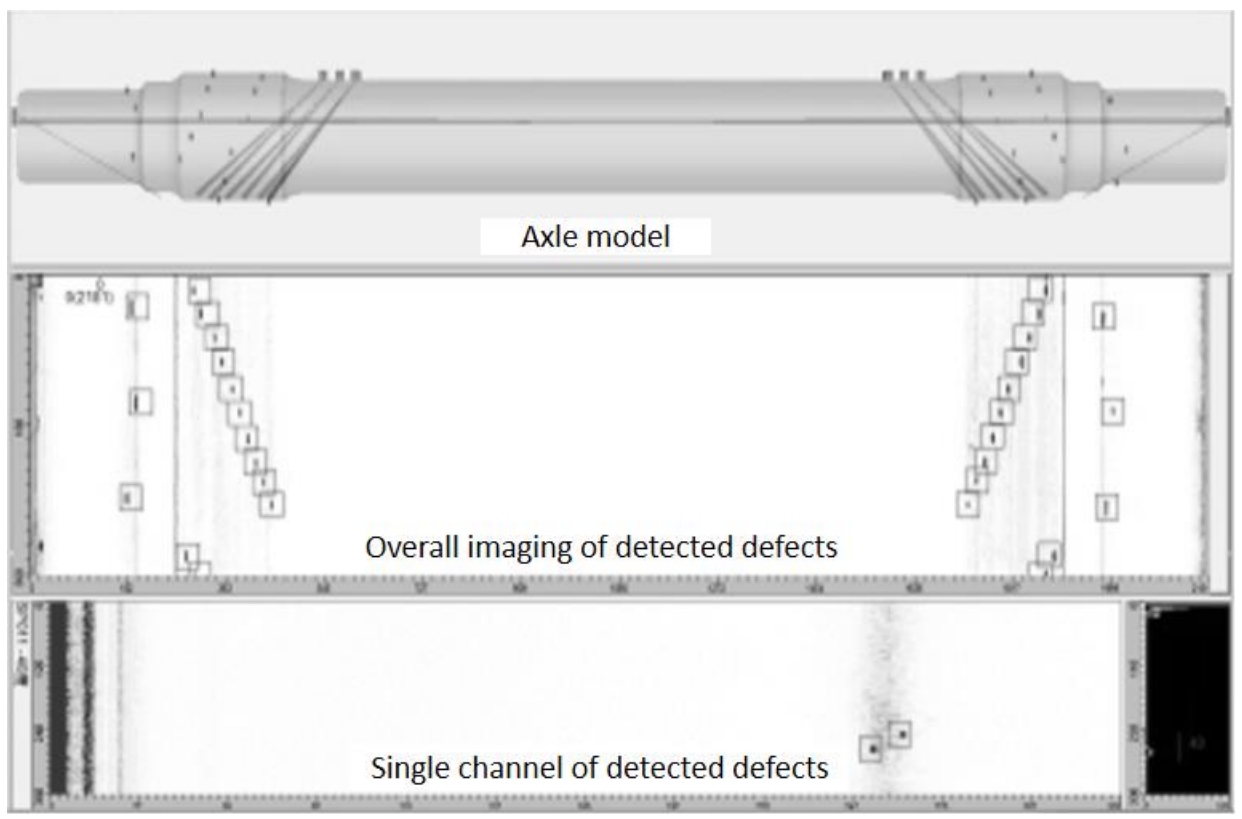

Fig.2 Calibration result display of automatic ultrasonic detection equipment 


\section{CHINESE JOURNAL OF MECHANICAL ENGINEERING}

Vol. xx No. x, 2020

The fabrication of defects and the assembling of wheel-set are according to the relevant requirements of 'Railway general transportation [2013] no. 191' file which formulated by China railway corporation.

Due to the existence of objective reasons such as oil and rust penetration and fretting corrosion[6], when detecting the axle of wheel-set which have run for mileages[7], the ultrasonic detection waveform component is complex, which makes it difficult to identify whether there are defects in the axle.

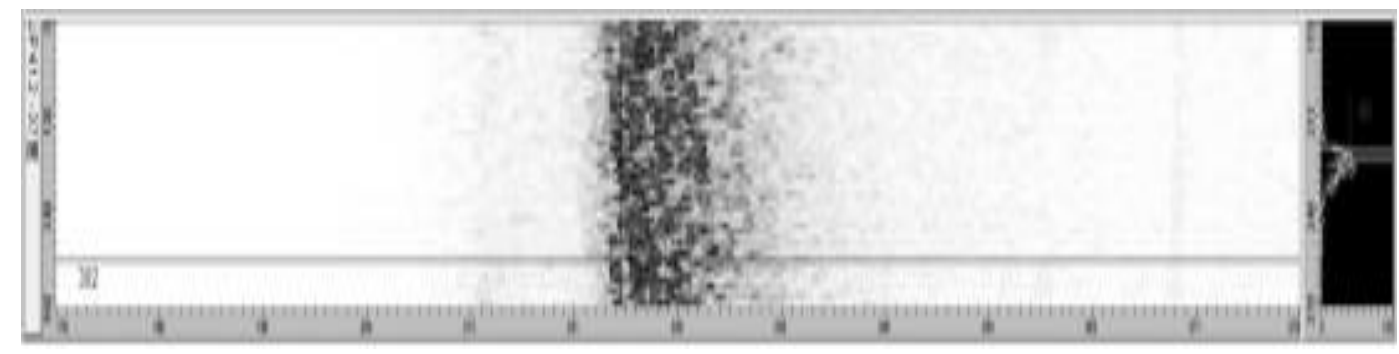

Fig.3 Detection result of axle inlaid part with oil and rust penetration

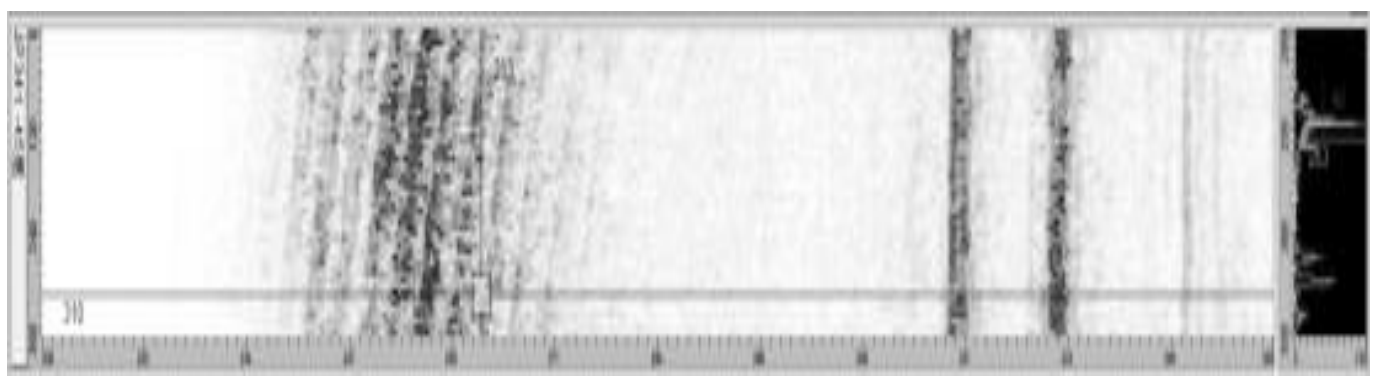

Fig.4 Detection result of axle inlaid part with tool marks

\subsection{Defects detection of axle inlaid part}

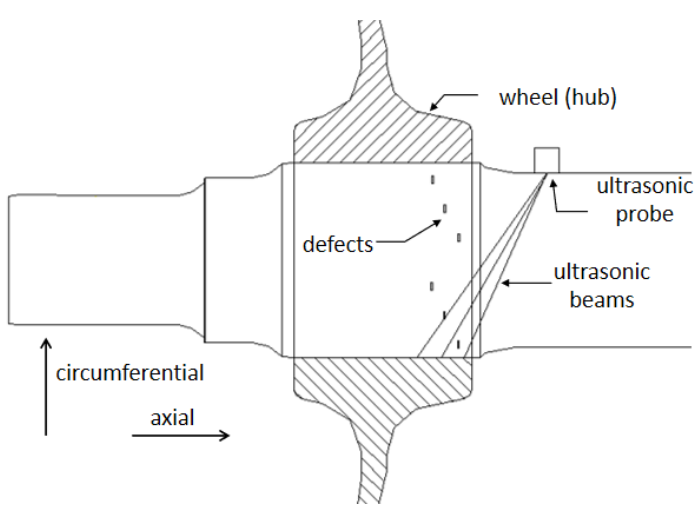

Fig.5 layout of defects
There were three each of $0.5 \mathrm{~mm}$ and $1 \mathrm{~mm}$ depth artificial crack defects(fig5), of which width was $0.2 \mathrm{~mm}$ in axle inlaid part which is pressed into wheel by interference fitting method to assemble a wheel-set, and installed on a test platform for fatigue increment running to simulate the actual situation showed in fig3, the oil and rust penetration and fretting corrosion cause the high energy noise, of which waveform can submerge the waveform of defects if there were fatigue defects[8] so that the misjudgment occurs. 
The area of defects was detected by ultrasonic probe on the axle body, the detection results were showed in fig6 and fig7, the detection result of $1 \mathrm{~mm}$ depth defects shows high amplitude, high SNR and easy to identify,

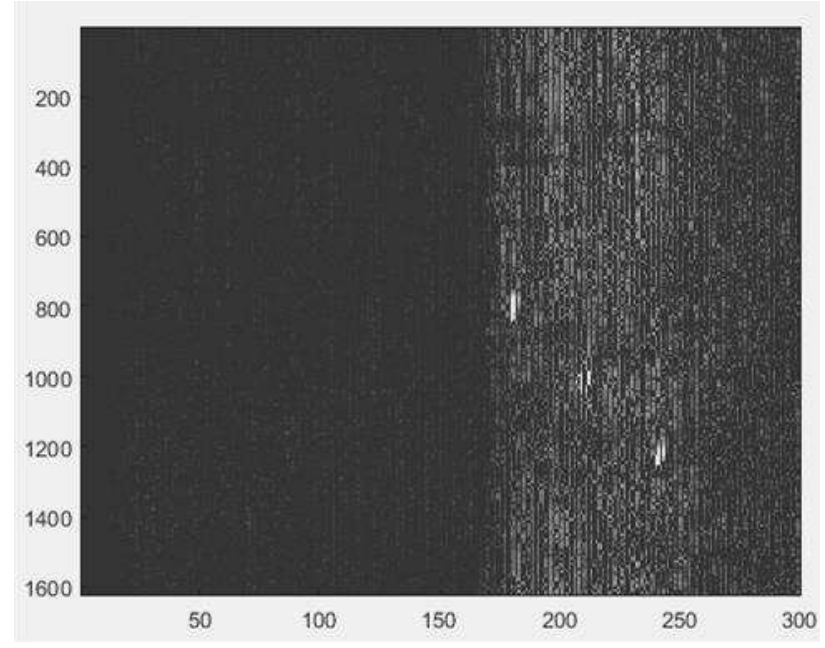

while the detection result of $0.5 \mathrm{~mm}$ depth defects shows low amplitude, low SNR and hard to identify, the waveform of defects were submerged in noise and the display is similar to fig7, which was without defects .

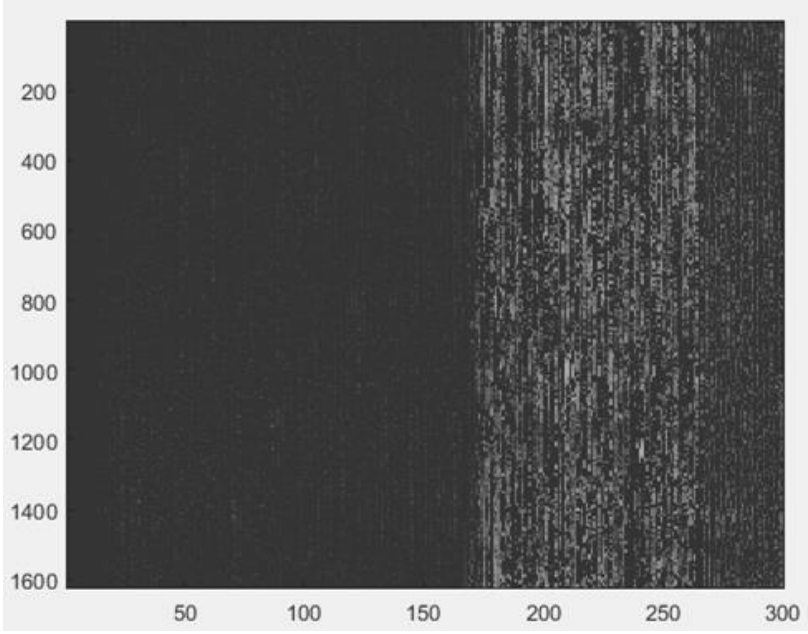

Fig.6 Detection result of $1 \mathrm{~mm}$ and $0.5 \mathrm{~mm}$ depth defects in axle inlaid part
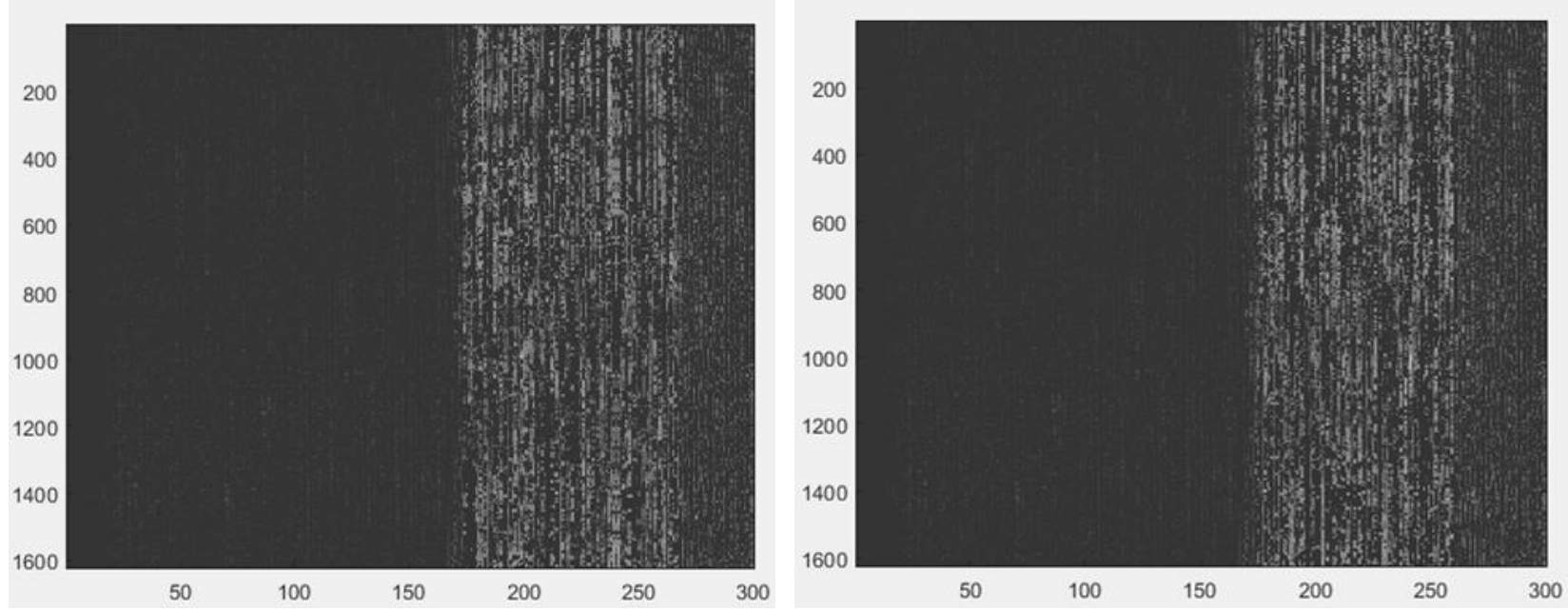

Fig.7 Detection result of axle inlaid part without defects

\section{Automatic judgment}

\subsection{Wavelet analysis of defect characteristics}

Base on Fourier transform[9], frequency domain analysis of signal play an important role for traditional analysis and process of stationary signal, but it's an integral transform for the signal in full time domain, for non-stationary signal, it doesn't have time and frequency localization function, and can't show the essence characteristic of the signal at a certain moment. 


\section{CHINESE JOURNAL OF MECHANICAL ENGINEERING}

Vol. xx No. x, 2020

Wavelet[10]transform has the function of time-frequency analysis, which can realize the time-frequency localization analysis of decomposed signals. The defect detection signals showed in fig6 are decomposed by db5 wavelet basis with 4-layer. Because of the equivalent and position information of defects were known, the obvious defect characteristics was found in the
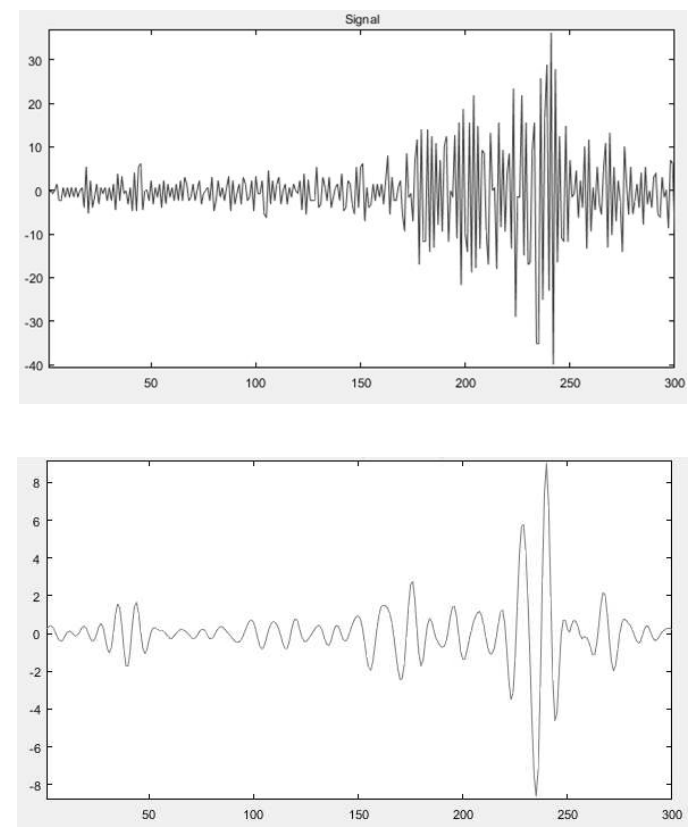

detail coefficient of 3 and 4 layers by analyzing the obtained wavelet coefficients. The figure below shows the comparison between the waveform of defect detection and its reconstructed waveform with the reconstructed detail coefficients of wavelet decomposition. The reconstructed waveform has a better SNR and time-domain position characterization.
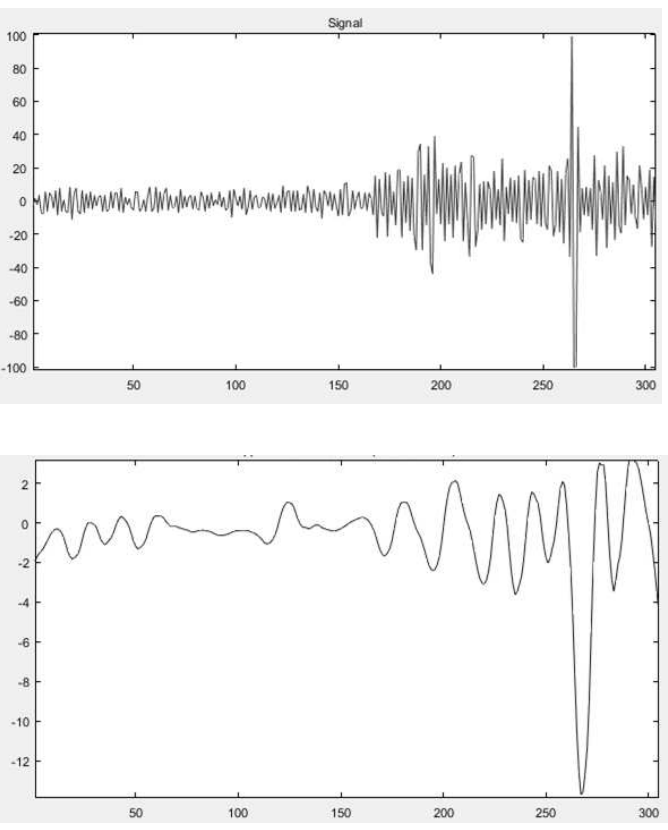

Fig.8 Defect waveform(above) and its reconstructed waveform(below)

\subsection{Judgment of detection for axle} inlaid part

Filter the detail coefficients before reconstruction by wavelet self-optimization threshold function[11], as shown in equation (1). The reconstructed waveform data can be served as the discrimination basis for whether there are defects or not, so as to realize the effect of automatic judgment of detection for axle inlaid part.

$\hat{w}_{j, k}=\left\{\begin{array}{l}0,\left|w_{j, k}\right| \leq M \cdot T, \\ \operatorname{sgn}\left(w_{j, k}\right) \cdot \max \left(\left|w_{j, k}\right|-N \cdot \frac{\sigma^{2}}{s}, 0\right),\left|w_{j, k}\right|>M \cdot T\end{array}\right.$
And, $w_{j k}$ is the transformed wavelet coefficient, $j$ is the decomposition layer, $k$ is the data point numbers of the wavelet coefficient, $\sigma$ is the noise intensity of the actual signal, $M$ is the adjustment parameter of the threshold value $T, N$ is the gradient of the contraction of the adjustment exponential function between the soft and hard thresholds, and $M, N$ can be optimized based on the positive correlation between the correlation coefficient and the SNR. The expression of $s$ in equation (1) is equation (2). 


$$
s=\sqrt{\frac{1}{2} \cdot \max \left(\frac{1}{n} \sum\left(w_{j, k}\right)^{2}-\sigma^{2}, 0\right)}
$$

The figure below displays the automatic judgment results of the $1 \mathrm{~mm}$ and $0.5 \mathrm{~mm}$ depth

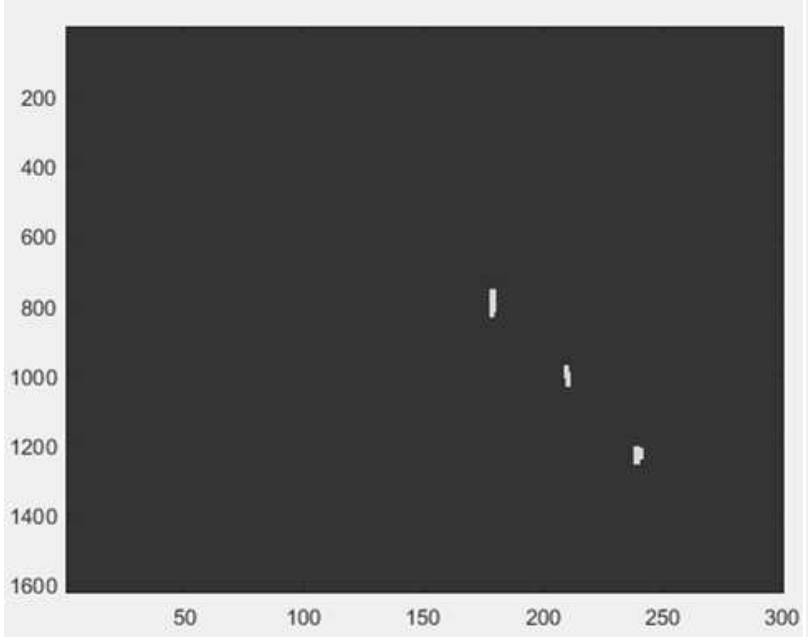

defects in axle inlaid part showed in fig6. It can be seen from the result that all defects of different positions and equivalents in axle inlaid part can be effectively identified[12].

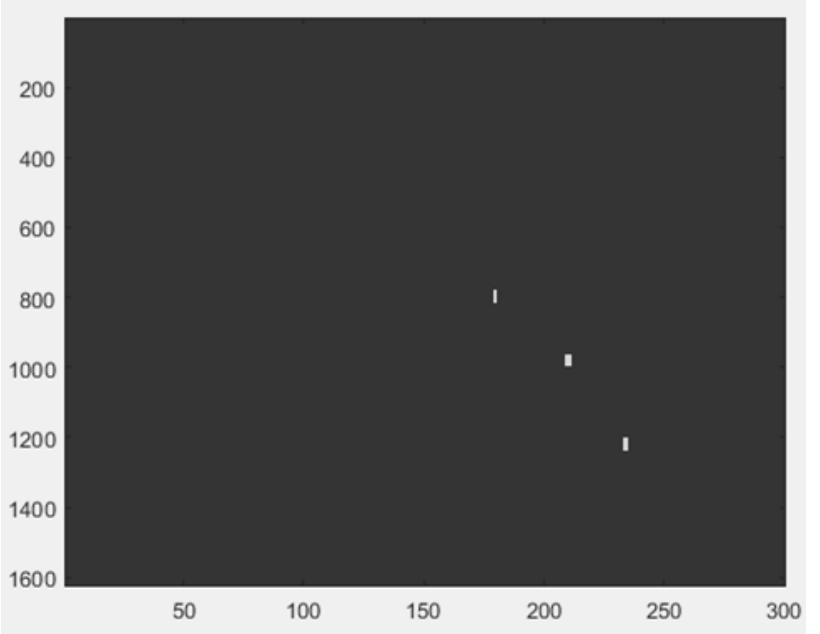

Fig.9 Automatic judgment result of $1 \mathrm{~mm}$ and $0.5 \mathrm{~mm}$ depth defects in axle inlaid part

\section{Conclusion}

When detect the axle inlaid part with ultrasonic method, there are wide range and high energy reflection waveform caused by interference assembly of axle and wheel, oil and rust penetration and so on. So it is very difficult to identify the defects with the traditional judgment method by amplitude and shape of waveform, while misjudgment may occur. In view of the above phenomenon, this paper proposes an automatic judgment method of ultrasonic detection for axle inlaid part by using the main characteristics of defect as judgment basis. This judgment method has been verified that the defects in axle inlaid part could be identified automatically and distinctly. The main content of this paper:

(1) Base on the characteristics that signal can be decomposed by wavelet transform in time-frequency domain, the wavelet coefficients of defect characteristics can be extracted;

(2) Reconstruct wavelet coefficients of defect characteristics which filtered by self-optimization threshold function to obtain distinct waveform of defects;

(3) Base on the judgment method described in this paper, the known defects which are at different position and different equivalents in axle inlaid part can be effectively identified.

\section{Declaration}

\section{Acknowledgements}

The authors sincerely thanks to Professor Peng jianping of Southwest Jiaotong University for his critical discussion and reading during manuscript preparation. 


\section{Funding}

Not applicable.

\section{Availability of data and materials}

The datasets supporting the conclusions of this article are included within the article.

\section{Authors' contributions}

The author' contributions are as follows: Kai Yang was in charge of the whole trial; Dong-Dong $\mathrm{Wu}$ wrote the manuscript; Dong-Dong $\mathrm{Wu}$ and Li-Ming Xie assisted with sampling and laboratory analyses.

\section{Competing interests}

The authors declare no competing financial interests.

\section{Consent for publication}

Not applicable

\section{Ethics approval and consent to participate}

Not applicable

\section{References}

[1] CAO Qingsong, GUO Xiaobing, XIONG Guoliang. Prospects of fretting damage of the train key components interference fitted surface[J]. Journal of Railway Science and Engineering. 2015, 12(3): 663-669.

[2] Benjamin D, Farshid S, Sachin S.A numerical and experimental investigation of fretting wear and a new procedure for fretting wear maps[J].Tribology Transactions, 2012, 55(3):313-324.

[3] Alfredsson B.Fretting fatigue of a shrink-fit pin subjected to rotatory bending experiments and simulations[J]. International Journal of Fatigue, 2009(31):1559-1570.

[4] C. Peng, X. Gao, J. Peng, et al. Axle Defects Detection Optimizing by Phased Array Ultrasonic [C]. 11th IHHA, Perth, Australia, 2015.
[5] C. Peng, X. Gao, Y. Zhang, et al. Research of Phased Array Ultrasonic detection on Railway solid Axle [C]. 11th World Congress on Railway Reaserch, Milan, Italy, 2016.

[6] ZENG Fei, CHEN Guangxiong, ZHOU Zhongrong. Fretting analysis of interference fitting of wheel-set based on ANSYS [ $\mathrm{J}]$.Journal of Mechanical Engineering, 2011, 47(5):121-125.

[7] C.Michelei,C.Stefano. Advanced ultrasonic

"Probability of Detection" curves for designing in-service inspection intervals[J].International Journal of Fatigue 2016 Vol.86 P77-87 0142-1123.

[8] Y.Wu, B.Xiang. Comparison in Strength Design of Axles for High Speed Railway and Full-Scale Fatigue Test Methods[J]. Rolling stock. 2015, 53(6): 1-5.

[9] J.C. Kuo, C.H. Wen, C.H. Lin, and A.Y. Wu, VLSI Design of a variable-length FFT/IFFT processor for OFDM-based communication systems, EURASIP Journal on Applied Signal Processing, 2003, No.13, pp.1306-1316.

[10]J. Zhang, G. K. Lin, L. Wu, et al. Wavelet and fast bilateral filter based de-speckling method for medical ultrasound images[J]. Biomed Signal Process Control. 2015, 18:1-10.

[11]C.Peng, X.Gao, A.Wang. Novelwavelet self-optimization threshold denoising method in axle press-fit ultrasonic defect detection[J]. Insight, 2016, 58(3):145-151

[12]Yang Zhang, Weifeng Ding, Zhifang Pan, Jing Qin. Improved Wavelet Threshold for Image De-noising.[J].Frontiers in neuroscience, 2019 Vol.13 P39 1662-4548.

\section{Biographical notes}

Kai Yang, born in 1980, is currently a Lecturer Master supervisor at School of Physical Science and Technology, Southwest Jiaotong University, China. He received his doctor degree from Southwest Jiaotong University, China, in 2015. His research interests include sensor technology, nondestructive testing methods and the development of automation and information equipment in the field of rail transit safety.

\section{Tel:+86-13880769139;}

E-mail: yangkai swjtu@163.com

Dong-Dong Wu, born in 1982, is currently an engineer at Chengdu Lead software technology Co., Ltd,, China. He received his master degree on 


\section{CHINESE JOURNAL OF MECHANICAL ENGINEERING}

Vol. xx No. x, 2020

electronic information in Sichuan University, China.

E-mail: 555chip@163.com

Li-Ming Xie, born in 1988, is currently an engineer at Chengdu Tiean technology Co., Ltd,, China. He received his doctor degree on electromagnetic field and microwave technology in Southwest Jiaotong University, China.

E-mail: m15982309732@163.com 


\section{Figures}

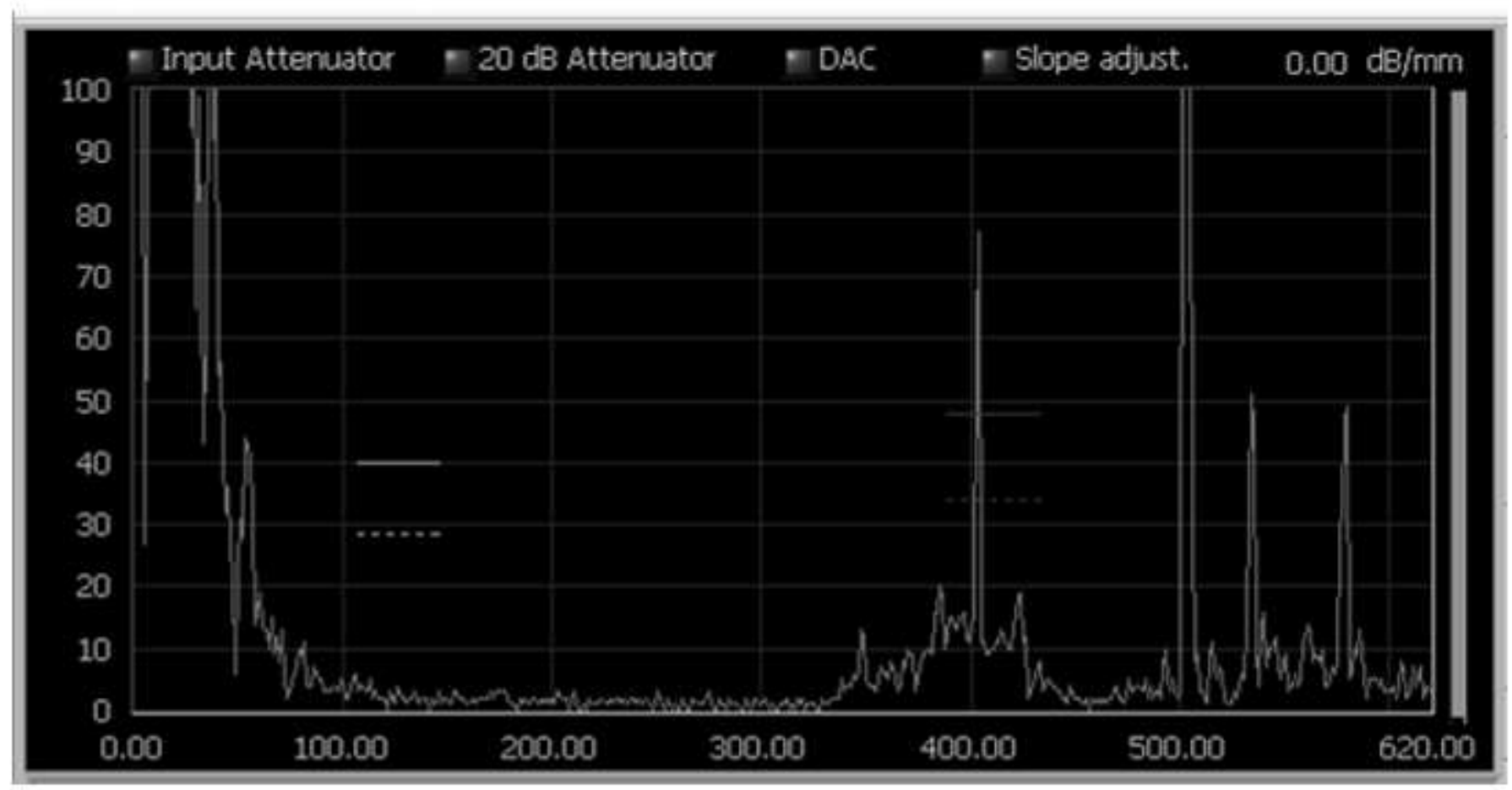

Figure 1

Conventional ultrasonic detection result(A-scan) 


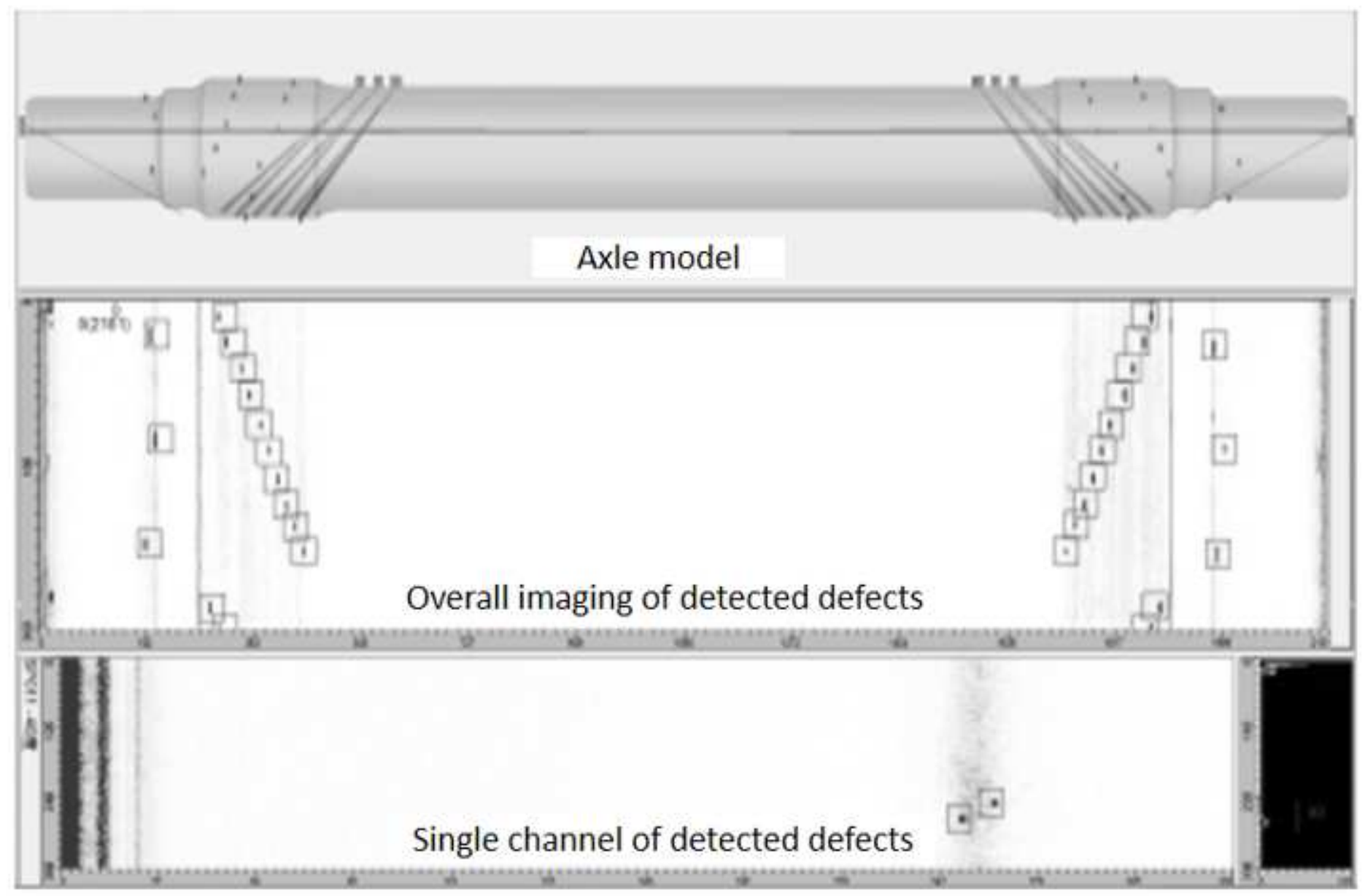

Figure 2

Calibration result display of automatic ultrasonic detection equipment

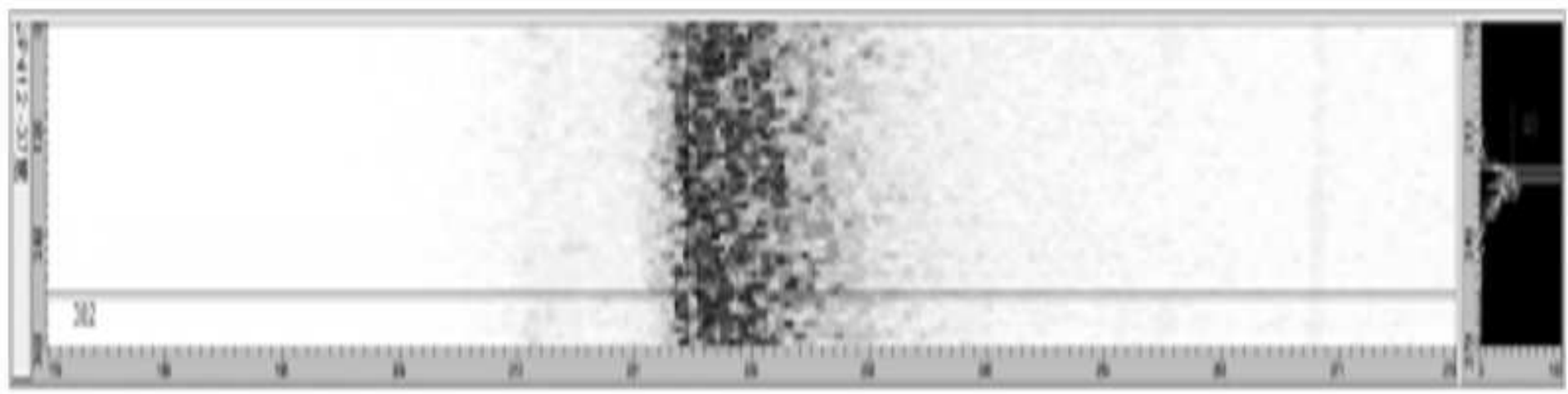

\section{Figure 3}

Detection result of axle inlaid part with oil and rust penetration 


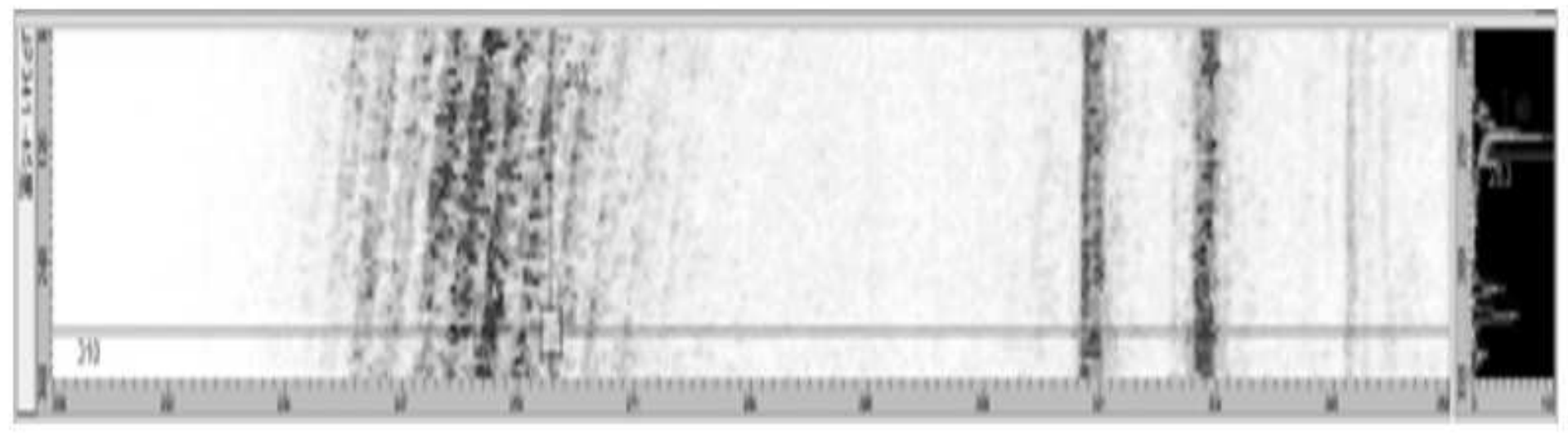

\section{Figure 4}

Detection result of axle inlaid part with tool marks

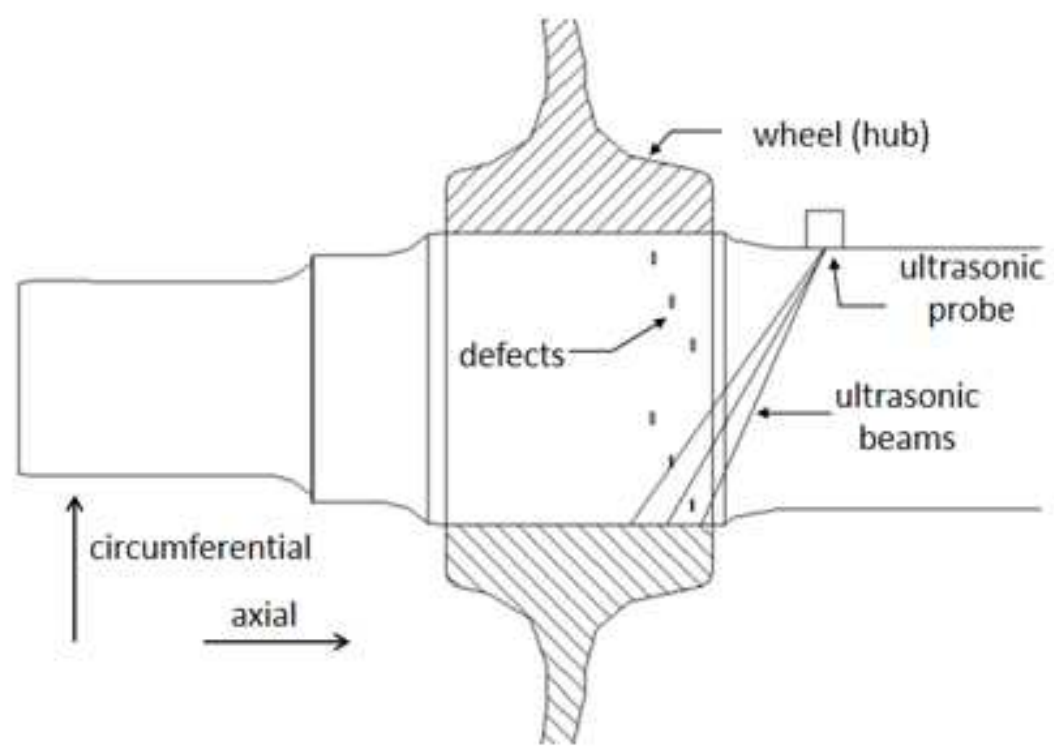

Figure 5

layout of defects 

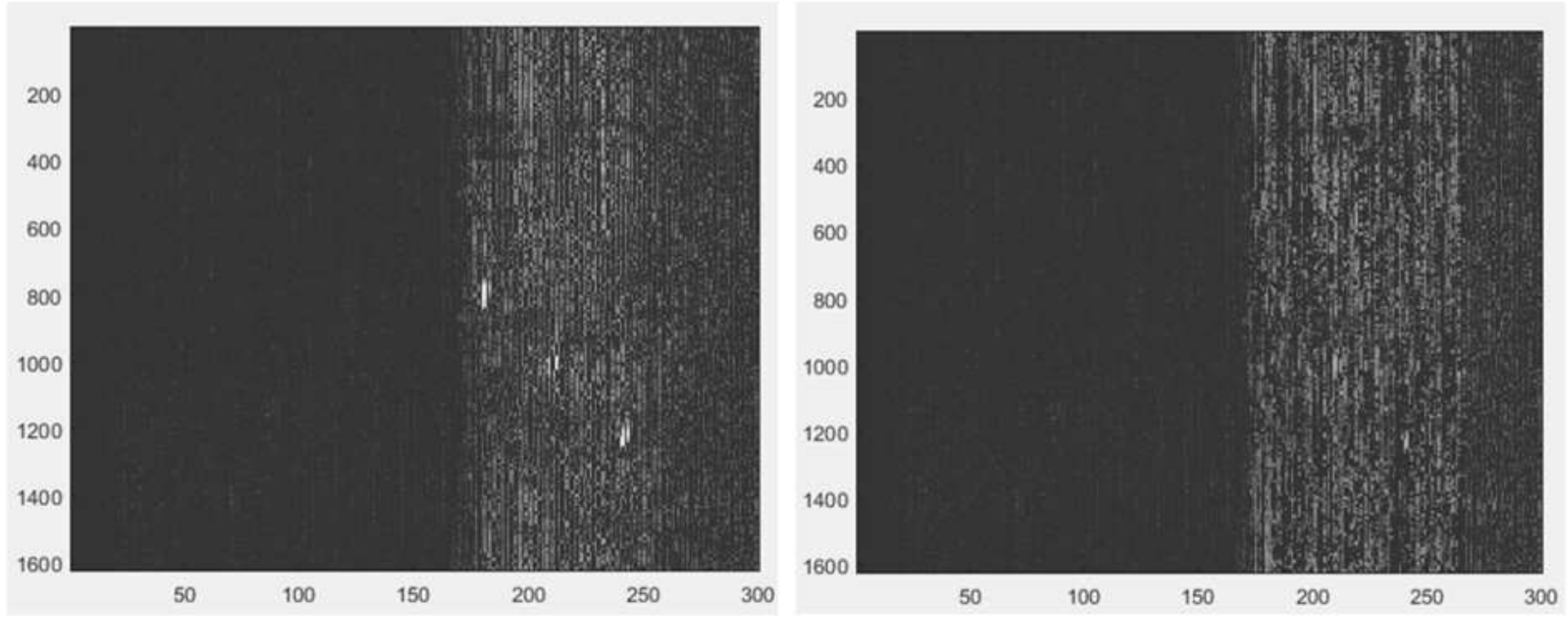

Figure 6

Detection result of $1 \mathrm{~mm}$ and $0.5 \mathrm{~mm}$ depth defects in axle inlaid part
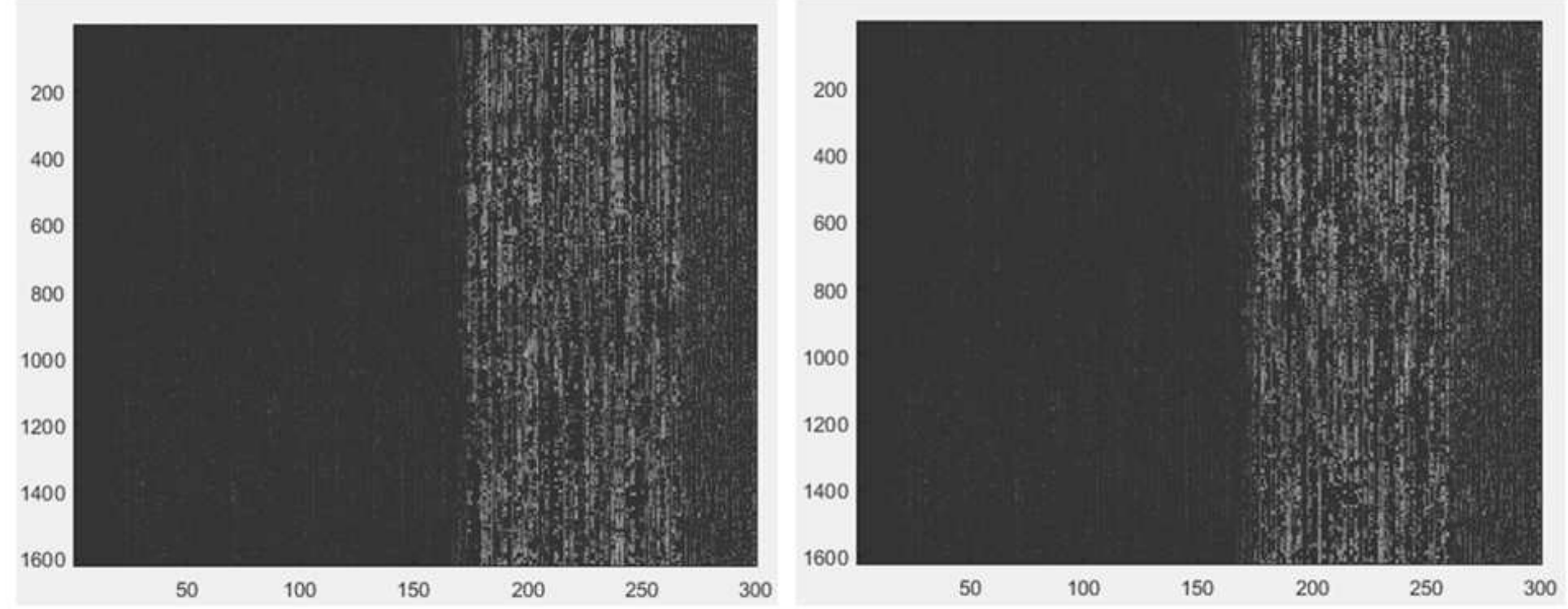

Figure 7

Detection result of axle inlaid part without defects 

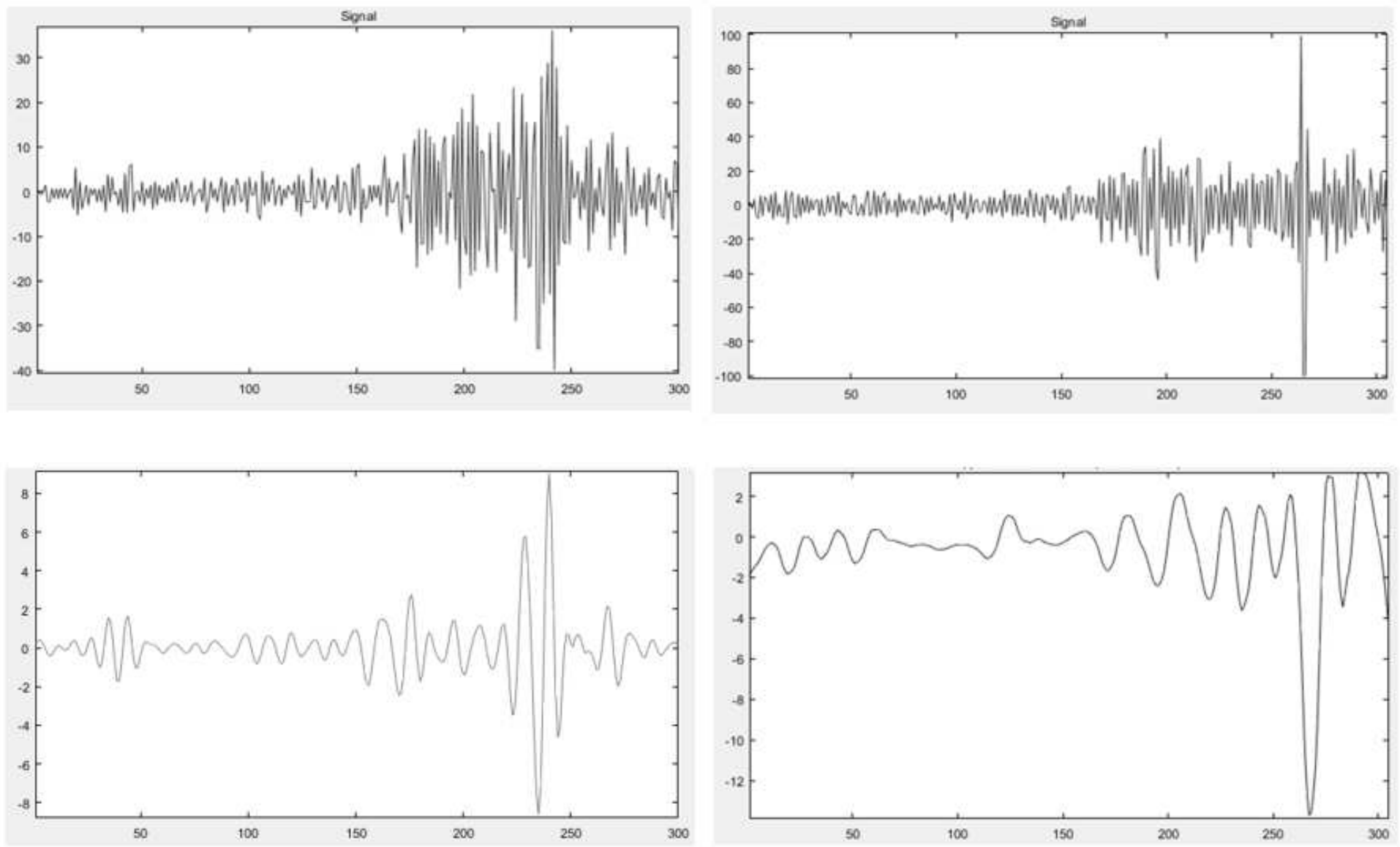

Figure 8

Defect waveform(above) and its reconstructed waveform(below)

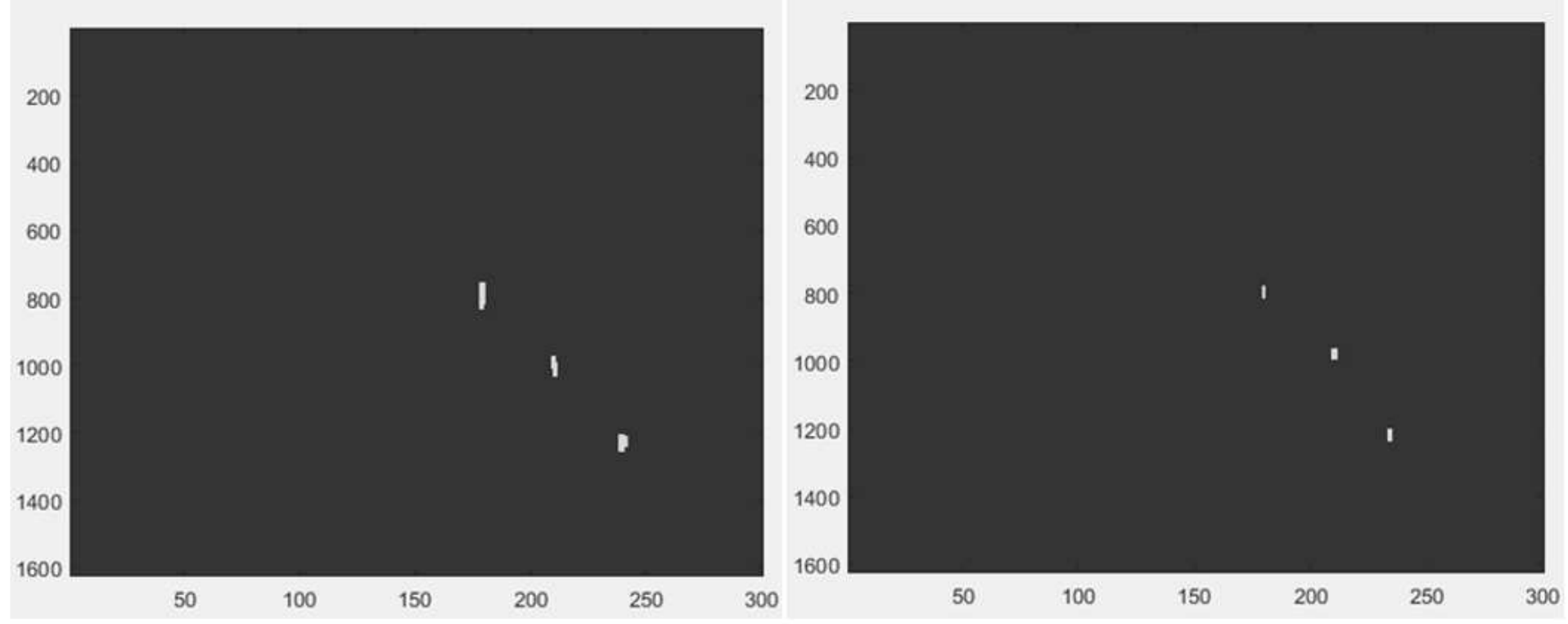

Figure 9

Automatic judgment result of $1 \mathrm{~mm}$ and $0.5 \mathrm{~mm}$ depth defects in axle inlaid part 